\title{
Changes in patterns of activity at a tertiary paediatric neurosurgical centre during the first wave of the 2020 pandemic
}

\author{
Ibrahim Jalloh $^{1}$ (D) $\cdot$ Helen Smart ${ }^{1} \cdot$ Katherine S. Holland ${ }^{1} \cdot$ Hannah R. Zimmer-Smith ${ }^{1} \cdot$ Rachel E. Isba $^{2}$ (D)
}

Received: 31 July 2020 / Accepted: 11 August 2020 / Published online: 18 August 2020

(C) Springer-Verlag GmbH Germany, part of Springer Nature 2020

Dear Editor:

On Wednesday March 11, 2020, the World Health Organization (WHO) declared a global pandemic of COVID-19 - the disease caused by SARS-CoV-2 - a novel coronavirus. In the UK, the first cases had been reported at the end of January 2020 and the first death in early March.

Whilst there is evidence that globally children and young people (CYP) so far represent a relatively small proportion of serious infections and deaths from COVID-19 [1], they have been impacted in a myriad of unexpected ways. This is reflected in the way that they have accessed healthcare (or more accurately, had healthcare accessed on their behalf). Changes in patterns of paediatric emergency department attendances [2,3], accessing of community care [2] and increased acuity at the time of attendance at hospital $[2,4]$ have all been reported. The epidemiology of specific pathology has also changed, for example, patterns of fractures [5].

In paediatric neurosurgery, some pathology might be expected to decrease as a result of pandemic interventions such as "lockdown", e.g. head trauma sustained outside of the home, but other pathology would be expected to continue at background rates, e.g. brain tumours. Other measures such as school closures will have resulted in decreased visibility of

Ibrahim Jalloh

ibrahim.jalloh@addenbrookes.nhs.uk

Rachel E. Isba

rachel.isba@lancaster.ac.uk

1 Department of Neurosurgery, Cambridge University Hospitals NHS Foundation Trust, Cambridge Biomedical Campus, Cambridge CB2 OQQ, UK

2 Lancaster Medical School, Health Innovation One, Sir John Fisher Drive, Lancaster University, Lancaster LA1 4YT, UK
CYP and disruption of access to normal sources of support, and this may have had an impact on presentations to neurosurgical services, e.g. abusive head trauma.

CYP under outpatient care and with direct access to a member of the hospital-based team might also engage with services in a different way during the pandemic, particularly early on when little was known about the impact on this age group.

We aimed, therefore, to describe patterns of urgent referrals and specialist nurse access at a UK regional paediatric neurosurgical centre in the first 6 months of 2020.

For urgent referrals received by the on-call paediatric neurosurgeon, data were examined for the 6 months January-June in 2020 and the same period in 2019. A 4-year mean for the first half of the years 2016-2019 was also used for comparison, to address the likely variation between years given the small numbers.

For the specialist nurse access (phone call data), a comparison was made between 2020 and 2019, and weekly data was also examined to allow for any background increase in calls in the second half of 2019. Calls were recorded as "answered", "busy" or "unanswered", and an assumption was made that they were independent events.

In the first 6 months of 2020, the centre received 226 urgent referrals, a decrease of $13.1 \%$ compared with the same period in 2019 and $7.8 \%$ compared with the 4-year mean. Compared with 2019, March and May had the biggest single-month decreases in referrals, each of about a third $(34.1 \%$ and $30.8 \%$, respectively). This phenomenon was also observed when compared with the 4-year mean, although the size of the decrease was reduced to $29.7 \%$ for March and $15.3 \%$ for May.

The most frequent urgent referrals, across all years, were for head injuries, including skull fractures and intracranial haemorrhages; hydrocephalus, including newly diagnosed hydrocephalus and shunt problems; and brain and spinal tumours. See Table 1. 
Table 1 Numbers of urgent referrals for the three most common categories of diagnosis

\begin{tabular}{llll}
\hline Number of referrals & & & \\
\hline Category & January-June 2020 & January-June 2019 & Mean January-June 2016-2019 \\
\hline Head injuries & 83 & 87 & 70 \\
Hydrocephalus & 72 & 97 & 87 \\
Brain and spine tumours & 23 & 20 & 27 \\
\hline
\end{tabular}

In the first half of 2020 , there were 2750 more calls to the specialist nurses than in the first half of 2019 (4291 vs 1541 calls). See Fig. 1. For $6.1 \%$ of callers $(261 / 4291)$ in 2020 , the line was busy which had not been the case previously $(0 / 3372)$. There were 2.8 times as many answered calls in the first 6 months of 2020 compared with the same period in 2019 (3460 versus 1258).

Our data reveals that during the first 6 months of 2020, referrals to the paediatric neurosurgical inpatient team decreased, particularly in March, when compared with 2019 and the 4-year mean. This is likely due to a combination of behavioural factors and may conceal some late presentations of important and treatable pathology. In contrast, calls to the dedicated specialist nurses increased several fold reflecting concern amongst parents and carers in a globally unprecedented scenario.

We acknowledge that our data is from a single centre; however, this pattern of reduced urgent inpatient referrals and increased demand for telephone advice is likely replicated across other tertiary centres around the world. This has implications for planning and delivery of services in future periods of lockdown. Proactively communicating with the parents/ carers of children known to the service is recommended to address concerns over the likely impact of COVID-19 on neurosurgical conditions.
Fig. 1 Number of calls made to the specialist nurse phone, by week and call status, January 2019-June 2020

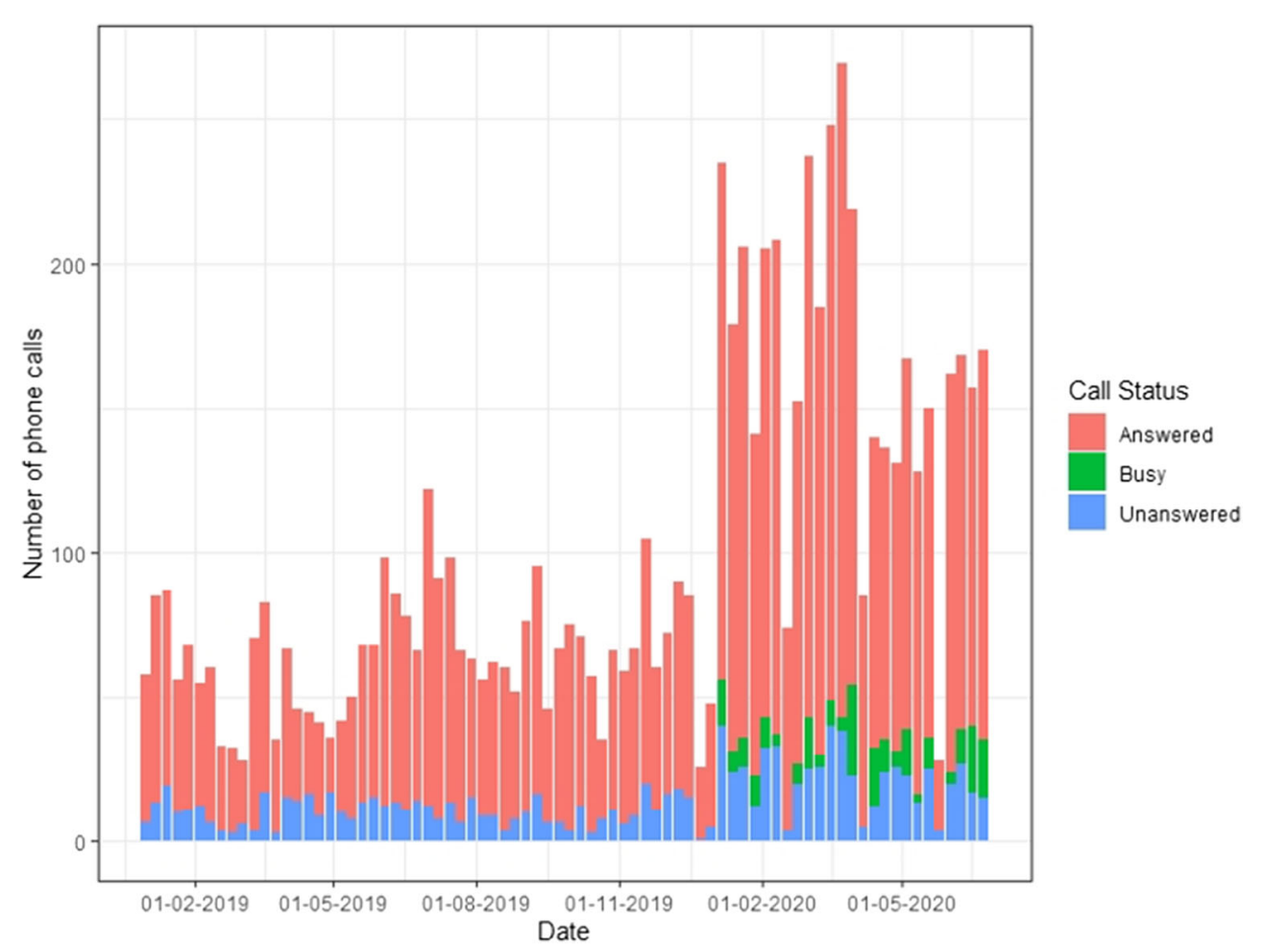


Acknowledgements Many thanks to Dr. Rhiannon Edge for assisting with data analysis.

Authors' contribution IJ, HS, KH, HZ-S and RI conceived of the idea; IJ, HS and RI extracted and analysed the data; IJ and RI wrote the manuscript.

Data availability Reasonable requests for primary data will be supported where possible.

\section{Compliance with ethical standards}

Count data only have been used, so ethics was not required. Patient consent to participate and for publication were not required.

Conflict of interest The authors report no conflicts of interest/competing interests.

\section{References}

1. Ludvigsson JF (2020) Systematic review of COVID-19 in children shows milder cases and a better prognosis than adults. Acta Paediatr
109(6):1088-1095 Available at https://pubmed.ncbi.nlm.nih.gov/ 32202343/

2. Lazzerini M, Barbi E, Apicella A, Marchetti F, Cardinale F, Trobia G (2020) Delayed access or provision of care in Italy resulting from fear of COVID-19. Lancet Child Adolesc Health 4(5):e10-e11 Available at https:/www.thelancet.com/pdfs/journals/lanchi/ PIIS2352-4642(20)30108-5.pdf

3. Isba R, Edge R, Jenner R et al (2020) Where have all the children gone? Decreases in paediatric emergency department attendances at the start of the COVID-19 pandemic of 2020. Arch Dis Child 105: 704 Available at https://adc.bmj.com/content/early/2020/05/19/ archdischild-2020-319385

4. Isba R, Edge R, Auerbach M et al (2020) COVID-19: transatlantic declines in paediatric emergency admissions. Under consideration by Pediatric Emergency Care

5. Bram JT, Johnson MA, Magee LC, Mehta NN, Fazal FZ, Baldwin KD, Riley J, Shah AS (2020) Where have all the fractures gone? The epidemiology of pediatric fractures during the COVID-19 pandemic. J Pediatr Orthop Available at https://pubmed.ncbi.nlm.nih.gov/ 32433260/40:373-379

Publisher's note Springer Nature remains neutral with regard to jurisdictional claims in published maps and institutional affiliations. 